\title{
Determination of Thorium in Native Gold by Radiochemical Neutron Activation Analysis
}

\author{
By Yongzhong Liu* \\ Department of Chemistry, The University of Electrocommunications, Chofu 1-5-1 Tokyo, Japan \\ and Urs Krähenbühl
}

Laboratorium für Radio- und Umweltchemie, Institut für Anorganische, Analytische und Physikalische Chemie, Universität Bern, CH-3000 Bern 9, Switzerland

(Received November 24, 1994; revised January 20, 1995)

Thorium / Protactinium / Native gold /

Radiochemical separation / Ion exchange /

Coprecipitation with tellurium

\begin{abstract}
Thorium concentrations in 11 native gold samples from different sources, e.g. placer gold, vein and lode gold were determined. Thorium was determined by radiochemical separation and measurement of protactinium from irradiated native gold samples. The chemical yield of the separation procedures is $90 \%$. Other elements were measured by gamma-ray spectroscopy.

The radiochemical separation procedures described in this work make accurate determination of Th concentrations in native gold at picogram concentrations possible.
\end{abstract}

\section{Introduction}

Gold, the first pure metal known to man, has occupied a special and unique position since ancient times, because of its status as a monetary standard. Gold plating depicted on monuments date back to about $3000 \mathrm{BC}$.

Native gold exists as metal in certain geological belts distributed across the earth's crust. The majority of gold occurrences are alluvial placer deposits [1].

Native gold is believed to be an excellent collector for volatile elements, which emanated from the earth's crust, in contrast to cogenetic silicate minerals, due to its retentive properties. Therefore, the age of formation of native gold is important for a better understanding of the evolution history of the earth. The formation age of native gold can be evaluated from the Th and $\mathrm{U}$ concentrations, together with the concentration of ${ }^{4} \mathrm{He}$ formed by $\alpha$ decay [2,3], if no He-losses occur.

The purpose of this work is to present a Pa separation method capable of determining Th concentrations at $\mathrm{ng} / \mathrm{g}$ level in very small native gold samples. The gold samples investigated in this work involved alluvial placer gold, vein type and lode type gold.

\section{Experimental}

A direct radiochemical determination of ${ }^{232} \mathrm{Th}$ is not sensitive enough, because of its low specific activity.

\footnotetext{
* Also at Institute of High Energy Physics, Chinese Academy of Sciences, P.O. Box 2732, Beijing 100039, P.R. China.
}

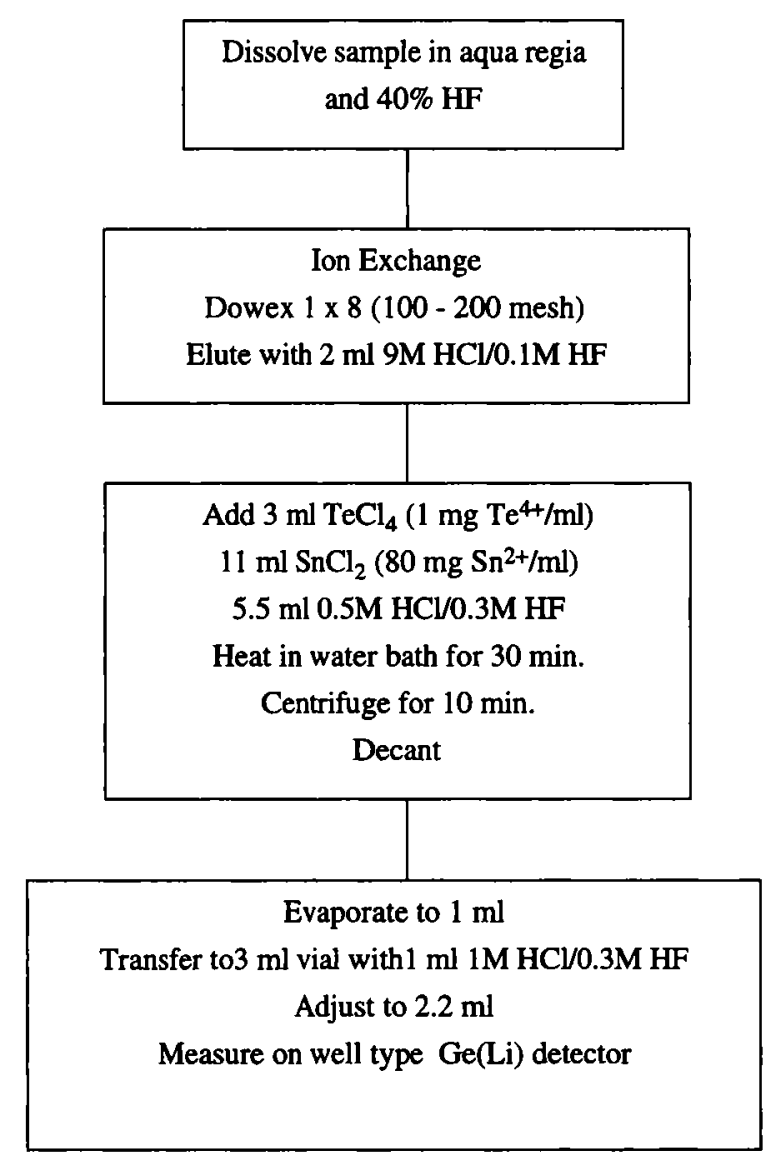

Fig. 1. Radiochemical separation and purification procedures for protactinium.

However, after irradiation of the native gold sample by thermal neutrons, Th can easily be determined by the $\gamma$-radiation of ${ }^{233} \mathrm{~Pa}$. The procedure and the activity measurement are illustrated in Fig. 1 and described in the following sections.

\subsection{Irradiation and dissolution of samples}

The native gold samples investigated in this work are rather pure metallic grains, normally with a size less than $1 \mathrm{~mm}$. They are listed in Table 1. 
Table 1. Th concentrations in native gold samples

\begin{tabular}{llccc}
\hline Sample name & Type & $\begin{array}{c}\text { Weight } \\
(\mathrm{mg})\end{array}$ & $\begin{array}{c}\text { Th } \\
(\mathrm{ng} / \mathrm{g})\end{array}$ & $\begin{array}{c}\text { U (ng/g)* } \\
\text { (range) }\end{array}$ \\
\hline Grosse Fontanne-1 & Placer & 18.96 & $135 \pm 5$ & \\
Grosse Fontanne-2 & Placer & 31.31 & $57 \pm 2$ & $50-3300$ \\
Grosse Fontanne-3 & Placer & 18.96 & $72 \pm 3$ & \\
Elvo-1 & Placer & 106.64 & $37 \pm 3$ & \\
Elvo-2 & Placer & 98.16 & $30 \pm 3$ & $130-670$ \\
Krümpelgraben & Placer & 34.34 & $285 \pm 11$ & $200-1300$ \\
Brusson & Vein & 27.47 & $1.2 \pm 0.2$ & $10-300$ \\
Lily & Vein & 10.03 & $2.3 \pm 0.6$ & \\
Sabie-1 & Lode & 8.55 & $11 \pm 1$ & $7-100$ \\
Sabie-2 & Lode & 10.2 & $9.3 \pm 1$ & \\
Bohemia & Placer & 24.99 & $38 \pm 4$ & \\
\hline
\end{tabular}

* The U concentrations were determined by isotope dilution mass spectrometry; but they were not performed on identical aliquots. From Eugster et al. [3].

The samples were sealed in quartz vials and then irradiated in the swimming pool reactor SAPHIR, of the Paul Scherrer Institute, Villigen PSI (Switzerland) under a thermal neutron flux of $5 \times 10^{13} \mathrm{~s}^{-1} \mathrm{~cm}^{-2}$ for 48 hours. $\mathrm{MgO}$ doped with a Th solution was used as a standard. The irradiated gold samples had a very high activity due to the large neutron capture cross-section of ${ }^{197} \mathrm{Au}$. However, as the half-life of ${ }^{198} \mathrm{Au}$ is only 2.7 days, the strong activity decreased markedly during a cooling period of 10 to 14 days.

The irradiated quartz vials were opened, $0.3 \mathrm{mg}$ of $\mathrm{Ag}^{+}$was added as carrier and the samples were dissolved with $80 \mu \mathrm{l}$ aqua regia in a $1.5 \mathrm{ml}$ Teflon vial. During this process a white precipitate of $\mathrm{AgCl}$ was formed.

It typically took 6 hours to dissolve the samples. The resulting solutions were evaporated to near dryness. Then $10 \mu \mathrm{l}$ of $40 \%$ HF were added to dissolve the remaining residues consisting presumably of refractory accessory minerals, such as zircons.

The resulting solution was evaporated to near dryness again, followed by addition of $50 \mu 1$ conc. $\mathrm{HCl}$, and evaporation to a volume of less than $10 \mu \mathrm{l}$.

\subsection{Separation and purification of protactinium}

The gold solution was loaded onto an anion exchange column (Dowex 1X18, 200-400 mesh, inner diameter $3 \mathrm{~mm}$, length $30 \mathrm{~mm}$ ), which was pretreated with $5 \mathrm{ml}$ conc. $\mathrm{HCl}, 2 \mathrm{ml} \mathrm{H}_{2} \mathrm{O}$ and $0.5 \mathrm{ml} 9 \mathrm{M} \mathrm{HCl} / 0.1 \mathrm{M} \mathrm{HF}$. $\mathrm{Pa}$ was eluted with $1.5 \mathrm{ml} 9 \mathrm{M} \mathrm{HCl} / 0.1 \mathrm{M} \mathrm{HF}$ at a flow rate 1 drop in $40 \mathrm{~s}[4,5]$, whereas $\mathrm{Au}$ was retained by the Dowex 1 X8 resin. The effluent containing $\mathrm{Pa}$ and small amounts of $\mathrm{Ag}$ from the partial dissolution of the $\mathrm{AgCl}$ precipitate by $9 \mathrm{M} \mathrm{HCl}$, was collected in a Teflon centrifuge tube for further purification.
At this stage, ${ }^{110 \mathrm{~m}} \mathrm{Ag}$ dominated the $\gamma$-ray intensity of the effluent, because of its long half-life and the relatively high thermal neutron capture cross-section of ${ }^{109} \mathrm{Ag}$. Therefore, $\mathrm{Ag}$ was removed with $\mathrm{Te}$, which was reduced with $\mathrm{SnCl}_{2}$ in $2 \mathrm{M} \mathrm{HCl}$ [6]. Two $\mathrm{mg}$ of $\mathrm{Te}^{4+}$ in $1 \mathrm{M} \mathrm{HCl}$ were added to the effluent in the Teflon centrifuge tube and were precipitated with $11 \mathrm{ml} \mathrm{SnCl}_{2}\left(80 \mathrm{mg} \mathrm{Sn} \mathrm{Sn}^{2+} / \mathrm{ml}\right.$ in $\left.2 \mathrm{M} \mathrm{HCl}\right)$. The addition of $5.5 \mathrm{ml} 0.5 \mathrm{M} \mathrm{HCl} / 0.3 \mathrm{M} \mathrm{HF}$ followed. Tellurium was formed and the solution was heated to near boiling for about $30 \mathrm{~min}$ to coagulate the precipitate. After centrifugation and filtering, the coprecipitation of $\mathrm{Ag}$ is repeated, in order to remove $\mathrm{Ag}$ completely. The resulting filtrate was evaporated to $0.5 \mathrm{ml}$, made up to $1 \mathrm{ml}$ by the addition of $1 \mathrm{M} \mathrm{HCl} / 0.3 \mathrm{M} \mathrm{HF}$ and transferred to a $3 \mathrm{ml}$ plastic counting vial.

The chemical yield for the complete separation procedure was $90 \%$. It was determined by independent yield experiments with tracers of ${ }^{233} \mathrm{~Pa}$.

\subsection{Sample measurement}

The samples were measured in a well type $\mathrm{Ge}(\mathrm{Li})$ detector. All samples and the standard solution were adjusted to $2.2 \mathrm{ml}$ in plastic vials. The purified samples were found to be of sufficient radiochemical purity. The most abundant $312 \mathrm{keV} \gamma$-ray of ${ }^{233} \mathrm{~Pa}$ was measured to calculate the Th concentration. Each sample was measured for at least 18 hours.

\section{Results}

The Th concentrations of the eleven native gold samples are given in Table 1 . The results vary within a range of 1.2 to $285 \mathrm{ng} / \mathrm{g}$. This variation reflects the differences in the origin of auriferous deposits, the evolution history of different types of native gold and the geologic environment of gold bearing locations. 
Sample Lily GM and Brusson of vein type gold have 2.3 and $1.2 \mathrm{ng} / \mathrm{g}$, respectively, the lowest concentrations among these samples.

Alluvial placer gold originates mainly from the primary vein and lode-type gold that have been subjected to several cycles of erosion, transportation and deposition $[7,8]$. Thus the differences among 3 Grosse Fontanne Placer samples might be explained as the result of heterogeneous mechanically rolling of refractory minerals with high density, such as zircons, into the gold. All Placer gold samples show significantly higher concentrations of Th and $U$ then any other type of gold. The goal of the investigation was to attempt direct dating of native gold based on the in situ production of He by $\alpha$ decay of Th and U [3]. But so far the $\mathrm{U}$, Th-He dating was not successful for several reasons:

- Some placer gold samples contain zircons that were mechanically worked into the gold grains during transport.

- Radiation damages in the gold crystal lattice cause loss of $\mathrm{He}$.

It is worth noting that the presence of small amounts of HF in the chemical procedures significantly improved the chemical yield. In the tracer tests without HF the chemical yield was only about $50 \%$ [9].

\section{Acknowledgement}

We owe many thanks to $O$. Eugster for organizing a joint study of noble gases and chemical composition of native gold. This work was supported by the Swiss National Science Foundation. The manuscript was improved by H. R. von Gunten.

\section{References}

1. Keays, R. R., Skinner, B. J.: The Geology of Gold Deposits: The Perspective in 1988. (R. R. Keays, ed.) Econ. Geol. Mon. 6, 1 (1989).

2. Eugster, O., Hofmann, B., Krähenbühl, U., Neuenschwander, J.: Nobel gases in alpine gold: U/Th-He Dating and Excesses of Radiogenic He and Ar. Meteoritics 27, 219 (1992).

3. Eugster, O., Niedermann, S., Thalmann, Ch., Frei, R., Kramers, J., Krähenbühl, U., Liu, Y. Z., Hofmann, B., Boer, R. H., Reimold, W. U., Bruno, L.: Nobel gases, K, U, Th and $\mathrm{Pb}$ in native gold. Submitted to J. Geophys. Res. (1994).

4. Türler, A., Wegmüller, F., von Gunten, H. R.: Fast Radiochemical Separation of Am, Pu, Np, U, Pa, Th, Ac and Ra in Heavy Ion Reactions with Actinide Targets. Radiochim. Acta 43, 149 (1988).

5. Kirby, H. W.: The Radiochemical of Protactinium. National Academy of Sciences, National Research Council, Nuclear Science Series. NAS-NS 3016, ed., Washington 1959.

6. Sandell, E. B., Neumayer, J. J.: Photometric Determination of Traces of silver. Analytical Chemistry 23, 1863 (1951).

7. Keese, G. O.: The occurrence of gold in Ghana. In: Gold 82: Geol. Geochem. Genesis Gold Deposits. Ol. Soc. Zimbabwe Spec. Publ. 1, 1984, p. 645.

8. Felice C. Jaffé: Gold in Switzerland. Econ. Geol. 84, 1444 (1989).

9. Phillips, G., Milner, G. W. C., Harwell, A. E. R. E. : Analytical Chemistry. In: Comprehensive Inorganic Chemistry, Volume 5: Actinides, Master Index (Bailar, J. C., Emeléus, H. J., Nyholm, S. R. and Trotman-Dickenson, A. F., eds.), Pergamon Press Ltd., Oxford 1973, p. 75. 
